\title{
Practices of Cross Cultural Collaboration in Sustainable Water Management in Bangladesh
}

\author{
Jaap M. de Heer \\ VU University Amsterdam \\ Andrew Jenkins \\ BRAC Dhaka
}

Water management is a serious issue concerning the well being of numerous people. Usually people expect their government to take care of water resources management. Governmental organizations however focus on large scale problems and on the main infrastructure of their country. They also suffer from financial constraints and bureaucratic procedures resulting in little attention for local water problems. The last 10 years, initiatives were organized to develop a people oriented approach to local water management. This article shows an initiative developed in Bangladesh with support of The Netherlands. It presents an interesting case of cross cultural collaboration regarding local sustainable water management and through that of improvement of living conditions of Bangladeshi people. "What is characteristic for the concerned strategy and change processes and for this type of cross cultural cooperation" is our central question. First we present a theoretical exploration. Next, the case study shows a pilot project for the introduction of participatory water management in Southern Bangladesh. Cross cultural collaboration is illustrated by the concept of participatory water management, blending Bangladesh National Water Policy with Dutch ideas and experiences. The findings show characteristics of cross cultural collaboration in relation to strategizing and changing to introduce participatory water management.

\section{INTRODUCTION}

Bangladesh is a densely populated, developing country that not only tries to cope with poverty and serious economic and societal problems but also with the severe natural conditions which make the country prone to flooding and setbacks. At the same time this country is both blessed, and cursed, by its water resources: abundant water flows feed agricultural lands during the four month long rainy season. The same water however can cause floods and destruction, both by rivers and by the sea. Lack of rain and low river flows during the 8 month dry season can cause droughts and famine. Climate change is likely to make these natural phenomena even more 
extreme. Management, operation and maintenance of the thousands of kilometres of dikes and other infrastructure are of crucial importance.

The People's Republic of Bangladesh, or in Bangla (Bengali language) the Gana Prajatantri Bangladesh, is spread out over 147,570 square kilometers where about 160 million people live. $80 \%$ of the Bangladeshi's rely every day on water infrastructure (embankments, sluices, irrigation and drainage canals) for their livelihood and safety. This includes the entire population of Dhaka, the capital with around 12 million inhabitants. In a normal rainy season up to $30 \%$ of Bangladesh is under water, this can increase to $50-60 \%$ in an extreme flood year. The coastal area of Bangladesh is growing by some $35 \mathrm{sq}$. km per year. Bangladesh could create even more land and outpace the effects of sea level rise through innovative river and coastal zone management. These facts show that water is of crucial importance for Bangladesh, as it is intrinsic to agriculture, livelihoods, health, transport, economic activities and culture. Adequate water management is therefore probably the most important factor in the fight for food security and against poverty in the country. The devastating floods and famine which ravaged Bangladesh in 1974, proved to be a turning point in the history of water management in the country: it was obvious that drastic improvements had to be made in order to prevent such catastrophes from happening again. The events prompted the start of the Netherlands-Bangladesh cooperation in the water sector.

For a long time the Bangladesh Water Development Board has taken care of water resources management all over the country. Government as well as the local people are convinced however that this cannot be completely done by the national government alone. People's participation and contribution in water management is very much needed at the local community level and is increasing in Bangladesh. The government's National Water Policy (1999) and the Guidelines for Participatory Water Management (2000) form the policy and legal framework for this approach. The problem appears to be how to organize the local level involvement in water management in a sustainable way. In that respect, initiatives were organized to shape and apply a new people oriented approach to water management. The project of this case was developed with support of The Netherlands. It was meant to make a serious move to elaborate and apply an adequate approach for introducing integrated sustainable water management and through that to improve the living conditions of the Bangladeshi people in their areas. By organizing the water management organization at the local and regional level, the mobilization of local people would be possible in small scale water management activities, such as division of water, water supply, water levels, water quality, operations and maintenance, decision making about financial contributions etc. The case study concerns a pilot project for the introduction of participatory water management (further labelled as PWMP: Participatory Water Management Project) in 9 polders in the South of Bangladesh, in Khulna and Patuakhali Districts.

The project commenced in November 2003 and was scheduled for a period of five years. The project finalized its activities in 2009 but because of the appreciated outcomes, it started up again in 2010 in new areas. PWMP aims to assist the national water board to find a practical way to introduce realistic, affordable and sustainable participatory and integrated water resources management. PWMP has drawn extensively on lessons learned both from projects executed in the past and those which are continuing. PWMP is a pathfinder programme, in that the strategy being developed is based on actual practical experience which is expected to be applied all over the country. So the challenge of the project is to test the participatory water management approach in different locations and situations in the field, generate lessons to strengthen the water management capacity of both local water management organizations and national bodies. 
The question in this article relates to this: "what is characteristic for the concerned strategy and change processes and for this type of cross cultural cooperation?"

The case deals with societal and organizational change in a complex environment. Societal change takes place in a number of polders where special organizations have been formed in order to change peoples' 'deep structures', the way they usually behave in relation to water and the water infrastructure. Strategizing and changing are involved in the project approach regarding the local level and because the project also develops and strengthens the institutional capacity of the national water board in order to move towards a situation where this organization is able to effectively implement sustainable participatory water management as indicated in the national water policy. The case study deals with a complicated process because Bangladesh is one of the poorest countries in the world and has struggled with water management for a long time. The complexity is enhanced by the complex governmental, institutional and societal context as well as the working environment of PWMP, being situated in an 'old' organization with a vast bureaucracy where innovation, approval of proposals and activities are normally very time consuming.

\section{EXPLORING SENSITIZING CONCEPTS RELATED TO THE PWMP CASE}

The reasons for the desired change in this case are twofold. One is that participatory water management is demand driven. Local people, time and again, indicated that they have their own experience and knowledge of their area and ideas about the infrastructures needed for their safety and for reaching a better livelihood. They to some extent also want to be involved in realizing this. At the same time they understand that they are not able to build large structures or take up costly measures e.g. regarding erosion protection or land reclamation. So they are aware of the necessity of change and of cooperation with other organizations to realize this change and also to cooperate with national institutions in relation to the realization of larger works. The second reason for introducing participatory water management is that from a national level point of view it is impossible and undesirable to take care of the micro level water works. Besides, the National Water Policy prescribes decentralization of national tasks to the local level. The local level works however do influence water management on a larger scale so there has to be a good tuning of works and an adequate cooperation to achieve sustainable integrated water management. In order to organize itself and to achieve its goals, strategy, collaboration and change are central items of interest in this case. These concepts will be explored as sensitizing concepts which direct our attention to and make us sensitive for important dynamics.

The PWMP approach is in fact a project based intervention in day to day activities and behaviour of local people. Projects may be defined as "organizational constructs, based on a temporary connection between people, which are created in order to establish a more or less unique product or service". (Van Marrewijk and Veenswijk, 2006) The unique services of the project in this case are:

- piloting the implementation of participatory water management in 9 polders near Khulna and Patuakhali

- testing the participatory water management approach in the field, generating lessons to strengthen the planning capacity both of local water management organizations as well as national bodies.

Integrated water resources management means a multi-disciplinary approach of water problems e.g. from engineering, environmental, economic, agricultural or spatial planning points 
of view. Water problems may vary from water safety against flooding (by water from rivers or the sea) to problems of drought (scarcity of drinking and irrigation water) to water pollution. Piloting and testing means here in the first place that the whole concept of participatory water management had to be introduced and organized in a sustainable way in 9 areas where people were totally unfamiliar with it. Secondly, it means that lessons and best practices had to be derived from the new experiences in these 9 areas. This is important to decide whether or not the concept of participatory water management would be suitable for diffusion all over the country. The interesting point in this case is that in a process of close collaboration a participatory water management approach has been constructed based on new ideas and insights but also on practices and experiences from past processes characterized by cultural change.

To explore the question formulated in paragraph 1 in relation to the dynamics and changes PWMP is dealing with, we discuss three theoretical concepts regarding the strategy, process and practices of PWMP:

1. Aspects of Strategy Development in the view of 'Strategy as Practice'

2. Cross cultural collaboration and the 'Politics of Culture'

3. Change viewed as a Revitalization Process.

\section{Aspects of Strategy Development: 'Strategy as Cross Cultural Practice'}

One can see strategy in terms of an intended path of organizational activities that lead eventually to a realized objective. In this way strategy is seen as a plan which has more or less predictable outputs. Strategy can also be viewed as a pattern that emerges over time. (e.g. Mintzberg et al.1988). A sequence of activities can form a pattern that, when looking back in time, indicates a form of realized strategy. Both definitions seem valid because organizations have intended plans for future activities, as well as having patterns that evolve from their past activities. Strategy as perspective is another way of interpreting strategy. In our case, the perspective can be seen in the intentions and aspirations of the initiators of PWMP to contribute to a reduction of extreme poverty and to reduce the vulnerability to disasters and climate change. In the 'strategy as practice' approach, Johnson et al. (2007) view strategy as an ongoing process of strategic actions. They focus on what actors really do in the actual strategy process or in Minztberg's words on 'the crafting of strategy'. Strategy is not something an organization per se has and owns, as being an asset of some kind, strategizing is something that organizations and people in organizations 'do'. Therefore strategy development can be reflected upon as an activity within an organization, as ongoing interaction and sense making between people, rather than seeing strategy as property or a calculated position of the organization. Johnson et al. argue that what is missing currently in the field of strategic management is the emphasis on what people do in relation to strategy making. They view the process of strategy making as quite complex and not the result of an on-off switch. Nor can strategies be seen as decisions only being made by top management and then simply travel down the hierarchal ladder, which is often assumed in the strategic management literature (Johnson et al. 2007).

We view strategy as a process of sense making and reality construction, an ongoing crafting process of thinking, interacting, sense making and acting. Strategy is in that respect an intervention process, often aiming at initiating change in relation to contextual developments and future perspectives as well as fundamental renewal or innovation. Strategic change and choices may be seen as attempts to change current modes of cognition and action. That's why strategy development is a sensitive process given different views and cultural backgrounds in relation to involved stakeholders with their interests in choices to make. The politics involved in the 
processes in our case refer to power relations within the project team and in relation to its stakeholders, empowerment of the people, constitution of new water management organizations at the local level, with new jobs and functions to be divided up. An interesting issue is that the existing organizations in the water sector have to adapt their modes of operation to a new situation of participatory water management at a local level. These organizations have to decentralize tasks and adapt to the changing demands of local people who will be trained and organized. The possible inability to adapt to this can be found in a 'cultural lock in' (Burke, 2008; Foster and Kaplan 2001). 'Cultural lock in' refers to 'the gradual stiffening of the invisible architecture of the corporation and the ossification of its decision making abilities, control systems and mental models...' This prevents organizations from making necessary innovations in terms of its products or services, and shedding operations with less promising futures (Foster and Kaplan, 2001).

\section{Cross Cultural Collaboration and the 'Politics of Culture'}

Complex cross cultural collaboration processes and the practices used in this case clearly illustrate the social dynamics in and around organizations and evoke associations with the idea of 'social becoming': a continuous stream of events based on actions, micro politics, choices and changes related to the network and context in which they happen. (Sztompka, 1991). Collaboration can be viewed as a process of social becoming in the perspective of ambitions or goals to achieve and of the practices as they unfold (Björkeng, Clegg and Pitsis, 2009). In many situations collaboration appears to be not as evident as is suggested in much organization and management literature. It appears to be a real challenge with difficulties at individual, team, organization and network levels and it is therefore complex as well as problematic from an achievement oriented point of view. Complexity in interaction, decision making and collaboration increases strongly when more levels are involved and when differences of interests, opinions, norms, values and or basic assumptions become predominant in day to day activities. When differentiation or fragmentation between (sub)cultures are considerable, actors constantly face the features and practices of their different (sub)cultures and try to deal with these in constructing their intentions, loyalties and actions in projects and processes they are involved in. Especially in situations of high fragmentation e.g. in a loosely coupled network with relatively autonomous actors, the debates about uncertainties or inconsistencies and maybe confusion, ambiguity about positions of actors towards important issues, are normal aspects of organizing and changing also in relation to cross cultural cooperation.(Martin, 2002; Meyerson and Martin, 1987).

Organizing and leading large projects and complex processes of decision making and change, often incorporate interaction and negotiation with a number of actors with different cultures. The concept of cross cultural collaboration basically relates to these differences and to gradations of integration, differentiation or fragmentation as well as to the attempts of actors to deal with the different features and practices in a purposeful way. The question is, what purpose and whose purpose is being served in these attempts? There are many examples of complex cross cultural collaboration that not only show significant differences in interests and in thinking and acting of actors, showing 'rational' behaviour to achieve a certain purpose but which also point to behaviour based on multiple interpretations accompanied by confusion, ambiguity, tensions, power play or conflicts between actors.(Carter, Clegg and Kornberger, 2008; Maitlis and Lawrence, 2003; Flyvbjerg, 1998). Actors follow the ideas and interests appreciated in their culture which, in the case of cross cultural collaboration, may lead to a struggle about ideas and 
practices to be followed. In this respect cross cultural collaboration can be typified by what De Heer (2009) called the 'politics of culture', the micro politics involved in sense making of actors, struggling with each other about their cultural differences, like differences of opinion, ideas, preferences, interests and beliefs, their concepts or practices, values, assumptions etc. (De Heer, 2009). The politics of culture easily leads to power play, to non-decision making and lengthy discourses or even to failure in the eyes of key stakeholders. Here a comparison can be made with the field of strategy development which also can be seen as a highly political process based on actors' differences in culture and interests (Carter, Clegg and Kornberger, 2008). In most cases, cross cultural collaboration concerns anything but rational behaviour or rational management which makes it an interesting field to study.

Cross cultural collaboration between different actors can be understood as a process of becoming, characterized by interaction which comprises multiple interpretations, ongoing exchanges of perceptions and aspirations, sense making of the situation leading to specific choices and actions. Especially when pressure of time, of interests, or of other significant issues, is involved, management and employees stand up for their interests and beliefs and debate them. This interaction is complex because not only the perceptions, interpretations, values, beliefs and interests of the actors involved are competing here, there is also the exercise of power in various forms and anticipation of this in the tactics actors make use of. Our discussion so far, suggests some dimensions of the concept of 'politics of culture' (De Heer, 2009):

- A number of actors from various networks or arenas, formal and informal, as well as 'under the stage' are engaged in the interaction processes and shape a discourse;

- Ambiguity as important feature in uncertain and controversial situations; actors mostly want to reduce or balance ambiguity and uncertainty and use various tactics to achieve this in order to deal with pressure and stress and to act in line with their interests and making sense of the situation;

- Actors experience tension, try to cope with stress and sometimes with a sense of insecurity, depending on the experienced nature and urgency of the situation;

- Competition and power play between actors exercising their power to influence perceptions, interpretations, aspirations, ideas, beliefs as well as choices regarding the initiation of a process, of procedures and possible concepts and objects to be dealt with in the discourse leading to certain outcomes;

- Sense making and sense giving, often related to narratives of leaders, gradually develop in interaction and discourse, which are meaningful for strategy, choices and action;

- Ongoing performance of recurrent social practices in a certain context leading to both reproduction and renewal.

This conceptualization of the 'politics of culture' in cross cultural collaboration processes clearly suggests that not only management plays a role in the interaction process and in the politics and discourse. Actors from various positions from within organizations or their networks may contribute to or intervene in the collaboration processes. (Carter, Clegg and Kornberger, 2008; Whittington, 2006; Rouleau, 2005; Maitlis and Lawrence, 2003; Orlikowsky, 1996, 2000; Flyvbjerg, 1998; Brown and Duguid, 1991). Johnson et al. point out in the 'strategy as practice' approach to the significance of sense making and initiatives from the various actors for strategic implications (Johnson et al. 2007; also Chaffee, 1985; Whittington, 1996). 


\section{Change Viewed as a Revitalization Process}

The aim of the project is to change the view and activities of the people in the different polders, their current modes of cognition and action, concerning participatory water management. The project-driven change process suggests a change process bounded and managed in a fixed time frame in which 'it has to happen'. There is a certain risk involved here that change may not be sustainable once the project is over. Weick and Quinn (1999) make a distinction between continuous change and episodic change. Continuous change is constant, evolving and cumulative and is mostly occurring in emergent and self-organizing organizations. It is a redirection of what is already under way. They argue that continuous change, constant adjustments, created simultaneously across different organization units can create substantial change, assuming that these different changes in the units are tightly coupled and interdependent. The looser the interdependencies, the less likely that overall organization change will occur. Episodic change is infrequent, discontinuous and intentional mostly taking place within inertial organizations according to Weick and Quinn. It usually occurs during periods of divergence when organizations are moving away from their former period of balance. This divergence is the result of a misfit between the organization's deep structure and the demands from the external environment (Weick and Quinn, 1999).

One of the change objectives of the PWMP is to empower the people in the polders of the project through the installation of formal and registered local Water Management Groups belonging to a regional Water Management Association. The different levels of success of participatory water management at the community level relates to the level of empowerment. (Narayan, 2002)

Empowerment and security are critical focus areas in the design and execution of poverty reduction strategies. According to Narayan empowerment can be defined as: 'the expansion of assets and capabilities of poor people to participate in, negotiate with, influence, control, and hold accountable institutions that affect their lives' (Narayan, 2002). A higher level of well being can be achieved when actors have influence on decisions and are able to represent their voices properly. Empowering poor people requires the removal of formal and informal institutional barriers that prevent people from taking action to improve their well being and limit their choice. Narayan (2002) distinguishes four important elements to incorporate empowerment in a change process. The first is access to information: information is a strong resource of power. A two way stream of information is required e.g. from the citizen to a government organization and vice versa. If the citizen is well informed it is easier to recognize and take advantage of opportunities, state services and to exercise his rights. Secondly, participation in decision making offers poor people control and authority which is important for their commitment to change. The third element regards accountability. When officials and leaders of an organization are held accountable, citizens experience this as safeguard against arbitrary action. Local organization capacity is the fourth element: 'this refers to the ability of people to work together and to mobilize resources to solve problems of common interests'.

In the change process in this case, people's participation is the core item. Related to this is the so called experience based design (e.g. Bate and Robert, 2007; Shedroff, 2001). The field of the 'experience-based design approach to organization change' consists of a loosely connected network of professionals, who describe their work in a variety of ways. What they have in common is their aim to improve users experiences of a service or product, trying to achieve this by making the user an integral part of the development process. Experience based design consists of two elements, a participatory element involving users directly in the process of design and 
development, and an experience element, aiming at improving the whole experience of a product or service. Participatory and collaborative approaches need to be incorporated within the strategy and change process to take advantage of user experiences.

Organizing change is one of the most studied topics in the study of organizing. Its roots are firmly anchored in still influential ideas of scientific and classical management concerning reengineering of organizational structures and working procedures or the remodelling of management rules and practices. The Human Relations Movement resulted in combination with early change models in practices and tools of Organization Development approaches which are still relevant today in organizing and guiding change processes (Burke, 2008). Theories of organizational change and strategy development arose after World War II. The debate focused in due course on questions of 'adaptation or selection' until the 1970s, 'transformation or evolution' during the 1980s and 'natural evolution or social dynamics' during the 1990s and later (Demers, 2008). Our approach is embedded in the social dynamics perspective, particularly the discursive and practice-centered approaches which originated in the 1990s. These approaches emphasize an interpretive understanding of organizations, viewed as cultures and interpreted as processes of becoming (e.g. Bate, 1994). Collaboration is one of the eminent processes of organizing, emerging out of and being an expression of the politics of culture. Organization and processes are understood as continuously re-created in ongoing processes of sense making embedded in an evolving discourse and in the micro politics as well as in practices of the actors involved. (e.g. Demers, 2008; De Heer, 2009; Carter, Clegg and Kornberger, 2008; Maitlis and Lawrence, 2003; Hendry, 2000; Gioia and Thomas, 1996; Gioia and Chittipeddi, 1991).

For our conceptualization of cross cultural collaboration and change as a process of becoming, throughout crafted in the 'politics of culture' and in the discourse of involved actors, a pattern of social change studied by Wallace (1956) offers interesting insights. Wallace uses the concept of revitalization to describe a pattern of social change, in fact a specific kind of intensified culture change. He studied from an anthropological point of view several hundred religious revitalization movements among both western and non-western nations. His analysis suggests a number of stages or even better, episodes in a revitalization process, indicated in Table 1.

Although Wallace was rather reticent about application of his findings to other areas than societal change, our experiences with cross cultural collaboration and organizational change support the pattern Wallace found (De Heer, 1991; 1998). We regard the revitalization concept to be important to understanding social dynamics of cross cultural collaboration in large projects and in change processes. Wallace however doesn't pay much attention to aspects of power which are inevitably involved in these processes. That's why it needs to be complemented by power play and politics as we discussed before concerning the 'politics of culture'. Another point is that the episodes in Wallace's revitalization process sometimes can take the shape of cycles instead of necessarily sequential phases. Phelan (2005) points to research and approaches of cultural change found by Kotter and Heskett (1992). In this research more than 200 enterprises and their change processes were analyzed in the period of 1979-1990. Phelan argues that the above discussed revitalization pattern shows similarities with the Kotter and Heskett findings and Kotter's approach in 'leading change'. (e.g. Kotter and Heskett, 1992, Kotter 1996). 


\section{TABLE 1 \\ STAGES OF REVITALIZATION}

\begin{tabular}{|c|c|}
\hline Stage & Description \\
\hline $\begin{array}{l}\text { 1. steady } \\
\text { state }\end{array}$ & $\begin{array}{l}\text { culturally recognized techniques for satisfying needs operate so } \\
\text { efficiently that chronic stress within the system varies within tolerable } \\
\text { limits. Gradual modification or even rapid substitution of some } \\
\text { techniques for satisfying needs may occur during this episode without } \\
\text { disturbing normal ongoing processes. }\end{array}$ \\
\hline $\begin{array}{ll}2 . & \text { increasing } \\
& \text { stress }\end{array}$ & $\begin{array}{l}\text { people experience that the efficiency of stress reducing techniques } \\
\text { decreases in certain periods in relation to various contextual agencies } \\
\text { leading to pressures and resulting in increasing stress, conflicts etc. }\end{array}$ \\
\hline $\begin{array}{l}\text { 3. cultural } \\
\text { distortion }\end{array}$ & $\begin{array}{l}\text { a prolonged experience of stress due to failure in need satisfaction and } \\
\text { to uncertainty and anxiety about expected change, results in cultural } \\
\text { changes, indicated by Wallace as active changes in one's 'mazeway' } \\
\text { (defined as mental image of the culture someone lives in, in relation to } \\
\text { the self) elements within the whole 'Gestalt' of the system. This may } \\
\text { form a serious distortion of culture when reduction of stress becomes } \\
\text { less adequate. In course of time people's anxiety for a less meaningful } \\
\text { life can become dominant, losing confidence in their culture, } \\
\text { becoming inactive in solving problems or in adapting their way of life. }\end{array}$ \\
\hline $\begin{array}{l}\text { 4. revitaliza- } \\
\text { tion }\end{array}$ & $\begin{array}{l}\text { consisting of 'mazeway reformulation' into an alternative and more } \\
\text { consistent and promising combination of cultural elements. The role } \\
\text { of a leader developing an alternative vision or editing a new narrative } \\
\text { is essential in this 'mazeway reformulation' because these impulses of } \\
\text { sense making by the leader and sense giving towards organization } \\
\text { members may offer opportunities for appreciated change and } \\
\text { development. }\end{array}$ \\
\hline $\begin{array}{l}\text { 5. intensified } \\
\text { change }\end{array}$ & $\begin{array}{l}\text { further elaboration of a new vision and communication with the } \\
\text { people are important to mobilize understanding and support to spread } \\
\text { and implement the proposed changes. Adaptation of vision elements } \\
\text { or of the strategy to realize these may need flexible adjustment } \\
\text { because of possible differences in opinion or even resistance to the } \\
\text { chosen direction and its consequences. Cultural transformation takes } \\
\text { place once the new 'mazeway' (or elements like a frame of reference, } \\
\text { a vision or a narrative) and the revitalization process gain broad } \\
\text { support as well as practical application. Day to day construction of } \\
\text { reality in line with the cultural change proves the effectiveness of the } \\
\text { new vision and revitalization in reducing stress-generating situations } \\
\text { and indicates routinization. }\end{array}$ \\
\hline $\begin{array}{l}\text { 6. towards } \\
\text { another } \\
\text { steady } \\
\text { state }\end{array}$ & $\begin{array}{l}\text { this episode arises when the cultural transformation has been } \\
\text { accomplished and social dynamics show mainly routinization and } \\
\text { gradual modification over time. }\end{array}$ \\
\hline
\end{tabular}


The discussed revitalization pattern, elaborated with the concepts of strategy as practice and collaboration characterized by the 'politics of culture' offer interesting sensitizing concepts for studying cross cultural collaboration in complex projects as well as processes of strategizing and changing.

\section{RESEARCH METHODS}

The research started in The Netherlands with studying many documents about the country and the project as well as with interviews with professionals in the field of organizational change and water management. The PWMP team provided a lot of reports from the project proposal to the latest evaluation report. Analyzing and discussing these documents with team members in Dhaka in 16 meetings and many informal discussions was very useful to learn about the water sector and its policies also in relation to people's participation as much as possible to understand the strategy and change process, its practices and interventions and to see the real meaning behind various activities.

Observations during 12 field trips were made to assimilate the knowledge of phenomena related to the social world of the people in the polders connected to the PWMP. The observation method was often used in combination with interviews in line with what Pader states: "we tend to categorize and develop implicit understanding of how important context, or situational behaviour, is for accurate category making and interpretations. Thus the things we observe in our direct context where we are at the moment, we analyze in order to understand the world around us' (Pader, 2006). In essence this is what observing is, making sense of the environment we are in.

One of the authors lives in Bangladesh for a long time and speaks Bangla fluently. The other author is a regular visitor of Bangladesh over the last ten years and was intensively involved in several processes of organizational change within the Government of Bangladesh. Both were closely involved in cross cultural cooperation regarding the PWMP. Their observations and experiences were widely used in this study. The research was mainly based on action research, many in-depth and focus group interviews. Being able to speak Bangla was crucial in communicating with local respondents and in translating stories, answers or remarks. The authors engaged in many discussions: at the level of the national government (Ministry of Water Resources), the donor community (especially with the Embassy of The Netherlands which initiated and co-financed the PWMP) and with the local people and the project staff. These interactions generated perspectives on how things worked in the project and in a wider meaning, also in Bangladesh at government level and in the field. It revealed in a lot of cases the purpose and strategies of people and organizations. Observations of an organization and society 'as it happens' provided useful information about the conditions, way of life, and how people interact with each other. Being there and being able to hear the "noise" and smell the "smells" helped in contextualizing the observed activities.

\section{THE SETTING OF THE CASE}

The PWMP case is an interesting one because it is a new step in organizing development cooperation concerning institutional change as well as a change of mindset of involved people in the water management organizations. It is not a traditional technical project. Development work has been executed in Bangladesh since its foundation but rarely with such a focus on institutional 
and participatory approaches. The water management projects in the past were mainly construction based. PWMP tries to use the gradually developing openness of the local people with a 'strategy as practice' approach: with a focus on action and practices, an experience based strategy development and implementation. The experience of participants of past projects and development programs is reflected in the new project team. The PWMP team was continuously evaluating their activities in order to refine the strategy. The project tries to ensure people's participation in all stages of water resources infrastructure rehabilitation. It also aims at sustainable water management in the selected sub-projects with active participation of people and to develop and improve local people's traditional knowledge, skill and capacity in planning, implementing and managing their water resources and systems. To reach these objectives, management responsibilities are (fully or partially) being transferred from the national water board to the people of the communities with their democratically established Water Management Organizations (WMO's).

However in practice participatory water management proved still a very challenging task. The infrastructure constructed during past projects was mostly not designed to serve multiple functions or uses, like facilities related to drinking water, or to agriculture in a broad sense (e.g. with differences between shrimp and rice farmers), fisheries, etc. Powerful groups could make use of this and operate the structures in their own interest. There were no devices in place to regulate this problem. The contradictory functions of water and interests of groups of people in a certain area could easily lead to conflict. So due to the lack of consensus only a limited number of people were really benefitting from the water infrastructure. Moreover, maintenance funds were low or were not available to keep the infrastructure in good shape. Consequently the infrastructure deteriorated, once more creating the need for a different approach to the development of water resources in order to tackle these issues. Improving the operation and maintenance of the structures was urgently required. The national water board responsible for this suffered however from low budgets. Problems with low attention and priority for small scale structures, together with poor allocation of the limited funds, together with unclear responsibilities and little accountability contributed to the maintenance problem at the community level.

In relation to this problematic situation a joint new project, PWMP, was initiated in 2003 by Dutch development cooperation, based on experiences with participatory water management in Bangladesh as well as in The Netherlands. PWMP was meant to tackle the issues of operation and maintenance at the community level or in relatively small schemes. PWMP resulted from two important policy documents approved at the end of the 1990s: the National Water Policy and the Guidelines for Participatory Water Management. Stakeholders or people's participation is of one the major changes in the new policies for the water sector in Bangladesh. It constitutes amongst other things, that local people, in the area where the water infrastructure exists, should have a part in the management of this infrastructure, defining them as local stakeholders. The change of policy forms a response to the mentioned issues of operation and maintenance. The new policy indicates that small scale maintenance and operation of the structure should be conducted by the stakeholders themselves on the basis of consensus and collective ownership. New projects were expected to have a multi-disciplinary approach to the various functions of water as well as to environmental issues and should incorporate this in their strategy and realization. According to the policy, operation and maintenance costs should be carried jointly.

The initial strategy and documents of PWMP were in accordance with the policy prepared by an experienced group of officers, selected and coordinated by an Additional Director General of 
the national water board who was strongly committed to a participatory approach to water management, together with an experienced Dutch economist. As a result, the strategy as formulated in a formal document which had to be approved by the government of Bangladesh was relatively simple and had clear perspective and objectives regarding participatory water management. It included both institutional change (within the national water board and in terms of local community organization) and practical interventions to demonstrate that sustainable water management could be made to work on the ground.

\section{STRATEGY AND PRACTICES OF REVITALIZATION}

\section{PWMP as Project Organization}

In 2003 PWMP was formed and for its implementation embedded within the national water board. The objective of PWMP as joint programme of The Netherlands and Bangladesh Government is to strengthen the capacity of water sector organizations especially the local level Water Management Organizations (WMOs) and local government institutions to a limited extent through an institutional framework and an integrated water resources approach.

A small but experienced team was recruited to elaborate this initiative into a process of strategy and decision making and implementation. Many of the team members had worked together before in the same field and looked forward to working together. Although this included a multi-national group of short-term international consultants (from the Netherlands, Canada, Philippines, Sri Lanka and Malaysia/India) all of them had previously worked in similar situations in Bangladesh, and the team leader (the only long-term expatriate) had extensive local knowledge and experience with the water sector of Bangladesh especially the national water board. The group of local team members, including engineers, sociologists, gender, environment and training specialists had also very extensive relevant experience and several had worked for many years in the same teams. Similarly, the staff assigned by the national water board to the involved Planning Directorate, which implemented this initiative had mostly been carefully chosen for their special skills in engineering, agriculture, economics, environment etc. and also for their experience and ability to contribute to a team.

The project organization consists of project management, the core team and supporting staff with a total number of about 20 persons. The team shows an experienced and dedicated mix of Bangladeshi and international members. PWMP was steered from some distance by the Embassy. Project management was taken care of by the team leader in close connection with a Director of the national water board. The team consists of a mix of private sector experts and government staff as well as female and male members.

The PWMP strategy embodies the creation of an enabling environment regarding integrated water resources management, environmental issues, dealing with institutional aspects and with a framework for implementation, establishing management instruments and procedures. Given the importance of women's role in water related activities (e.g. taking care of drinking water, food and crops), PWMP also focused on gender sensitivity and developed a gender strategy.

The team, strongly inspired by its team leader, developed in close interaction (by many discussions, workshops, draft documents etc.) a clear vision on the subject matter and initiated an innovative approach and a dedicated learning attitude. With the characteristics and experiences of the local situations in mind, the team operationalized their approach in suitable methods and practices accompanied by training modules regarding the involved issues. Activities team members were involved in are for instance developing and applying approaches and mechanisms 
for organizing people's participation and participatory water resources planning. Another major challenge was initiating and facilitating the establishment of water management organizations. Time consuming but very important were in this respect training and facilitating participatory water management activities on the local level. Because of the low level of education and illiteracy in the field, training needed to be very practical, making use of images, stories, learning by doing. Items to be discussed were for instance: what does participation mean for them, what is PWMP all about, how can people improve their situation by taking care of water resources together, how to organize meetings, choose a chairman, make decisions, collect financial contributions and properly take care of them, realize registrations, set up a planning and maintenance action plan, set up relationships with local government, the water board etc. etc. Besides there was much attention for realization and results, developing and facilitating participatory monitoring, training staff of governmental and local stakeholders.

\section{PWMP's Strategy as Practice Approach}

Based on progress in their learning process, the experience of earlier projects and of regular field trips as well as on the indications of the National Water Policy, PWMP-team members created a strategy with participation of local stakeholders or beneficiaries as a core element. The strategy was communicated and tested in workshops and in practice. It gained the support of stakeholders as well as of officials of the national water board and of the local people involved. They viewed this strategy as an adequate solution to deal with the problems of operation and maintenance of local water infrastructure.

There were also people with reservations who could not believe that the principles of participatory water management would survive in the long term once PWMP would have pulled out of the area. Some governmental institutions or officials were sceptical about PWMP and its efforts which caused debate and tension within PWMP as well as in the relation with the concerned actors. Also powerful landlords did not necessarily support the strategy because they would lose influence once a participatory water management organization would be dealing with 'their' affairs.

Experiences from close interactions with local people during the field trips with the entire project team were used to develop the strategy significantly. The PWMP team members often referred to these experiences as 'developing together'. They experienced and learned together the advantages and flaws of other projects and decided that they would like to have a more effective and people focused strategy. The PWMP staff really made an effort to change the approach of past projects by including the people in the design process of the strategy itself. Most of the team members and especially the project management showed a strong determination to create an approach in which the local communities played an important role. This contributes to the pathfinder role the PWMP was expected to play in terms of implementing the water policy. The team enjoyed this role and identity in the water sector. In this mood the PWMP people entered the polder areas for assessing situations, visiting old acquaintances and informing the people about PWMP while at the same time encouraging them to join the local water organizations to be formed. The PWMP team informed the people about the ideas of participatory water management and the objectives as well as procedures of the project in a simple manner with the aid of promotional material such as posters and leaflets. Moreover they emphasized the advantages of participation of the local community and explained how this could be achieved.

The PWMP strategy is reflected in practices belonging to six major steps, described in reports, and communicated in videos and brochures about PWMP. These strategic steps include 
all the ideas, knowledge, experience, methods and instruments of the team and form the basic approach of the project. Each step is in practice accompanied with an image to visualize the main activities; especially for the illiterate this is an adequate way to understand and remember the logics of the approach of PWMP. The strategy can be described as follows.

In the first step, Selection, which takes approximately two months, new projects or polders, in which water resources infrastructure rehabilitation and improvement activities could start are selected by members of PWMP. Selection is done on the basis of a survey and specific criteria regarding e.g. characteristics and specific problems of the area in which the polder is located, availability of existing organizations etc. to get the highest benefits for the lowest costs.

The second step is Investigation which takes about 6 months. At the start of this period a team of field investigators and representatives of the national water board have a meeting with representatives of local government institutions and of line ministries at community level to inform them that the water infrastructure in the polder will be rehabilitated. The participatory process in which this will take place is explained. Also the members of the community council are informed. Thereafter the field investigators of the project team have consultation meetings with male and female community members to collect basic information on the socio-economic, agricultural, livestock, fisheries, health, sanitation and environmental conditions. Simultaneously with this data collection, officers of the national water board, at divisional level, identify key water management issues and problems in each village through an engineering survey. All the collected data and information are processed and analysed by the multi-disciplinary planning team of the national water board. Based on a joint analysis (PWMP and water board) options for improved water management are developed and formulated in discussion and consultation with the local people.

Mobilization is a third step. This activity is closely linked with the previous step and is carried out parallel with it. The objective of this step is mobilization and social organization of the interest groups at community level. In order to do so, awareness raising activities are carried out at village level regarding the sustainable water management program. Water management groups (WMG's) are formed at village level. The WMG's represent all sections in the community and also include special groups such as landless people and destitute women. This is done to ensure that local community members (men and women) of all occupations and income levels actively and effectively participate in all stages of establishing sustainable water resource management. Each WMG forms an executive committee, through election or selection. It consists of 12 members representing the various groups in the village. At least $30 \%$ of the members of the Executive Committee are female. Additionally, a Water Management Association (WMA) is formed at the regional (polder) level through representatives from all the WMG's (one men and one woman from each WMG). This organization is established in order to involve all interest groups in the planning, implementation, operations and maintenance and monitoring of all activities at the regional level. Both the WMG and WMA formulate their own bylaws or rules and regulations. Ultimately, the bylaws are used to achieve the registration of these water management organizations and its members under Cooperative Act, with the Cooperative Department, which provides them with the required long-term legal status to work and to implement activities in cooperation with the national water board. Soon after the establishment of both types of water management organizations, training activities are started. An organization and management course is conducted for the Executive Committee members of all WMG's with the objective to develop and strengthen their organizing and management capacity. Training and capacity building is a continuing process and is therefore built into the 
following planning and implementation steps of the program as well. Capacity building includes formal and informal training, group discussions, workshops, exposure visits and on-the-jobtraining (learning by doing). A special focus is given to 'gender and leadership' training to encourage effective women's participation in decision making.

Fourth there is a Finalization (of the planning process) step. Based on the information gathered and problems identified in step 2, an integrated water resources management plan is formulated. This plan entails an Infrastructure Rehabilitation plan, a Sustainable Environmental Management Plan and an Operation and Maintenance Agreement between the WMA and national water board. The Infrastructure Rehabilitation Plan makes use of the socio-economic data, the environmental analysis (including an impact assessment and related mitigation measures), the water engineering survey and the analysis of the water management problems. It is the outcome of a consultative process between the WMA and community members; the planning team and the divisional staff of the national water board, in which various options to resolve the water management problems were discussed. The Sustainable Environmental Management Plan describes key environmental problems which are not directly related to the infrastructure improvement and proposes possible measures to resolve them. The plan further includes a timeframe for the implementation of identified environmental measures, identifies persons or organizations such as Local Government Institutions, other government departments (i.e. agricultural extension, environment, fisheries, forestry) and non government agencies who should be contacted for necessary cooperation and action. The Operation and Maintenance Agreement is a contract between the national water board and the WMA. It is the outcome of meetings and discussions held with the water management organizations, in which operation and maintenance issues are discussed and explained and options for resource mobilization for operations and maintenance are considered. The possible roles and responsibilities of the contract partners are described in the agreement.

The fifth step concerns Rehabilitation. Once the Infrastructure Improvement and Rehabilitation plan is formulated and approved it is implemented. Implementation of the plan includes modifications to the water management infrastructure so that it will be optimised, and ultimately leads to restoration of the infrastructure in the polder to full working condition for long-term operation. The infrastructure improvements are implemented in accordance with the plan by contractors and local contracting self-help groups, employing local workers including many women. The contractors will be involved in repair and construction of structures. The entire earthwork is carried out through local contracting groups, so that employment and income generating activities are provided to the poor sections of the community, and the quality of the work is assured. Assistance is given in the formation of local contracting groups, including training. The WMA selects from among its members a monitoring committee for observing the quality of work and to report the progress of the implementation to the WMA's, the WMG's and to the officials of the Divisional Office of the national water board.

Operation and maintenance is the sixth and final step of the strategy. Once the rehabilitation activities are concluded, part of the long term Operation and Maintenance responsibilities are, in line with the agreement, (see Step 4) transferred to the WMO. At the same time, the Sustainable Environmental Management Plan is implemented by the WMO with support from the Division Office of the national water board. Training courses are coordinated and organised by the planning teams to enable the WMO's to plan and implement regular maintenance, operation and monitoring. The training also focuses on strengthening the WMO's internal management capacity (leadership, conflict management, accountability, savings and income generation, etc.), 
increasing the membership of the organization (avoiding "free riders" in the community) and enhance external organizational contacts and linkages with other government and non government organizations. Once all infrastructural improvements have been carried out, participatory operation starts. During the first year the system is jointly operated and reviewed; shortcomings in the system are discussed and corrected. At village level selected members of the WMG are responsible for the operation of water infrastructures that affects the water levels of the land belonging to the village. At hydrological system level (blocks) a sub-committee of the WMA is formed under the WMA to manage the operations in this unit. The WMA maintains overall responsibility for the water management in the polder. The selected members who form committees are trained in gate and sluice operation and management, so that they are in a position to realize their operation targets through day to day operation of the structures.

\section{Specific Aspects of Collaboration}

Collaboration with the national water board was of vital importance because of its role in integrated water resources management all over the country. Integration of PWMP and the national water board was encouraged by sharing the same head office and working in functional groups, and by travelling and living together in the field. This helped to overcome possible negative feelings over significant salary difference (favouring the consultants) and differences in job security (favouring the government officers). From the beginning, the Director of the national water board and the expatriate team leader (who had worked together before) worked hard to encourage integration and cooperation between men and women, professionals of different disciplines and team members from different cultures and religions, and to discourage unnecessary conflict. Overall, in implementation PMWP followed ten explicit principles of cross cultural collaboration in this Bangladesh setting:

1. Be There (i.e. spend as much time as close to the real situation as possible)

2. Keep it Simple

3. Listen to the People

4. Understand the Problem Before Designing the Solution

5. Work with and share Clear Objectives

6. Maintain Consensus between Major Stakeholders

7. Work Together Creatively as Equals

8. Do not Reinvent the Wheel-Copy One

9. Plan Re-entry from the Start

10. Identify and Monitor Key Indicators

In particular, specific organized efforts were made to collect and evaluate relevant experiences from all over Bangladesh and elsewhere, and to make use of this experience. Unnecessary complications were ruthlessly eliminated and a very strong emphasis given to simple and sustainable procedures. A very strong emphasis was placed on encouraging the participation of women as well as men, and special efforts given to areas where cultural and religious attitudes initially made this more difficult. This emphasis enormously strengthened the participatory approach.

In addition to the team based in Dhaka, two teams, led by experienced professionals worked in the two field areas and had a high degree of operational autonomy. Good relationships, a commitment to cooperation, and modern means of communication made it possible for the central team to be requested for, and to supply, a high level of support to the field in solving a wide range of bureaucratic and other problems. 
In any activities in Bangladesh involving infrastructure and construction, corruption is an ever present threat. For participatory water management, this is a vital issue, since communities must have infrastructure build or repaired to a high standard in order to have the confidence and the practical capacity to operate and maintain it themselves. A combination of community organization, appropriate training, formal provisions for community representatives to monitor construction work, linked to a strong commitment from the central and local teams to integrity and transparency, and a 'zero-tolerance' policy concerning the Netherlands financial contribution, were integrated in such a way as to keep this problem under control.

Politics was certainly another problem. In the run up to 'engineering' the election expected at the end of 2007, the ruling party decided to 'nominate' the managing committees of the Water Management Associations. This was strongly contested with support from the national water board and the civil administration, and local politicians encouraged to stand in transparent and democratic elections instead. In practice, although water management organization leaders do sometimes have party affiliations, these do not count for much in a situation where leaders are judged by an aware and knowledgeable membership according to the real ability to manage operation and maintenance in a way which produces real community benefits.

The most important aspect of integration and cooperation was the participatory element in the approach. In the words of an evaluator, "this is an institutional project with an infrastructure component, not the other way round....".

In the words of a community leader in Polder 22,

"For the first time in this area we have all worked together to help ourselves: rich and poor, men and women, people from all professions and social levels; we have members who are farmers and fishermen, landless, destitute women, we have a doctor, I am a teacher...... think as our unity and confidence grows, we can do much more."

\section{EXPERIENCES AND OUTCOMES OF THE COLLABORATION}

It is now becoming clear that the revitalization strategy is producing tangible benefits in terms of increased production and economic activity, as well as poverty reduction in the polders. An independent study carried out by the Bangladesh Academy for Rural Development (BARD, 2009) found the following characteristics.

It is notable that opportunities for livelihood strategies were found to have increased in the study area after the PWMP interventions. Awareness of their situation and of the common interests opened up new ways of thinking and possibilities to improve together the livelihood conditions. Despite cyclone SIDR, housing conditions, especially the number of houses with tin roof and tin/wooden wall increased, which implies improvement in housing conditions over the last five years. The number of sanitary, water sealed latrines increased by over $20 \%$ in the Khulna and Patuakhali polder areas respectively due to increase of health awareness and changes in living standards.

Compared with the situation before PWMP, the total cultivable area of the respondents in Khulna and Patuakhali polder areas under F0 (flood-free) remarkably increased; the cropping intensity in all the sample polder areas increased in the post-PWMP period compared to prePWMP period. Total paddy production in Polder 22, Khulna, increased by $21 \%$ and in Polder $43 / 2 \mathrm{E}$, Patuakhali total paddy production increased by $34 \%$. Cropped areas and yields of oilseeds, 
pulses and vegetables also increased significantly. The FGD participants reported that fish cultivation in rice field increased in the villages under Khulna polder areas because of the opportunity of getting two valuable products rice-shrimp/prawn/fish simultaneously from a same piece of land.

There were remarkable positive changes in case of the indicators such as land productivity, fish availability, tree plantation, number of livestock, poultry and human disease after the PWMP. FGD participants opined that there were remarkably positive changes in all major indicators after PWMP interventions. Adjusted for inflation, there was an increase in average income over five years of $33 \%$ in the Khulna area and $22 \%$ in the Patuakhali areas. Demand for unskilled and skilled labour in the project area increased, which directly or indirectly contributed to the increase of investment, employment, production and income of the non-poor and the poor of the polder areas. Whereas before PWMP almost half of the households experienced endemic deficit, i.e. extreme poverty; after PWMP this had been massively reduced to one sixth of the total households.

The formation of Water Management Groups had a major impact on household saving, and the wage rate of male and female agricultural labourers increased remarkably during PWMP interventions compared to pre PWMP period. The husbands of many women of the PWMP polders areas started living as new households in the area after returning home due to generation of work opportunities in the PWMP polder areas. The highest proportion of the respondents mentioned that their economic condition improved due to increase of agricultural production and more involvement of people in agriculture mainly because of improvement in the water management. This has been made possible by continuing large increases in the maintenance contributions provided by local communities organized in water management groups and associations, in a situation where, previously, maintenance had been negligible, and infrastructure deteriorating rapidly.

Although in the agreements signed by the Water Management Associations and the national water board, emergency maintenance is the responsibility of the government, after the large surges caused by cyclones SIDR and AILA, the WMA's in all polders managed to close all the dyke breaches before they became to large to manage and so prevented long-term entry of saline tidewater into the farmland (in one polder they managed to close the dyke within 15 days, i.e. before the next spring tide). This contrasts sharply with experiences in polders in Khulna and Satkira Districts where participatory water management was not in place and breaches became very large causing long-term suffering to the communities. The strategy used to achieve these results relied on a high degree of integration, communication and collaboration at every stage and every level.

\section{DISCUSSION AND CONCLUSIONS}

The challenge of the discussed PWMP was to develop and apply a participatory water management approach in different locations and situations in Bangladesh, generating ideas, strategy and experiences to strengthen the water management capacity of both local water management organizations and national institutions. The question in this article relates to this: "what is characteristic for the concerned strategy and change processes and for this type of cross cultural cooperation?" In our theoretical exploration and (in fact limited) description of the case many characteristics were highlighted and elaborated. To present conclusions we go back to the discussed theoretical concepts: 
- Aspects of Strategy Development: 'Strategy as Practice'

- Change viewed as a Revitalization Process.

- Cross cultural collaboration and the 'politics of culture'

We refer on each concept to relevant characteristics and discuss these briefly.

\section{Cross Cultural Initiative of Strategic Importance for Strategy and Change Process}

An essential starting point of the introduction of participatory water management was the Bangladesh National Water Policy, approved in 1999. This provided from a strategic point of view an important way of thinking and an institutional framework for community participation. This policy already incorporates cross cultural influence about ideas and advantages of people's participation. The elaboration in 'Guidelines for Participatory Water Management' involved more people in this way of thinking and gives specific instructions on the legal basis for community organization and its legal relationship with government. However, policies and guidelines, no matter how good, do not bring about significant changes unless people and institutions make use of them. This is a very important and underestimated point. When the concerned people, organizations and management are not aware of a new policy or when they don't have the knowledge or means to carry it out or when they are not inclined to follow it nothing will happen at all. The strategy is on a shelve but it isn't a living strategy, action and practices are missing. In this perspective the joint initiative of committed people of the Bangladesh and Dutch governments to 'find the path' to making these policies and guidelines a reality was of crucial importance in terms of strategy as practice. The resulting strategy, documents and decisions were prepared by experienced people, selected and coordinated by senior management of the national water board. This means that after the strategic initiative the strategy development took place under positive conditions in which knowledge, experience but also the willingness and the power to act were combined with the strategic and financial support of a donor organization, the Dutch Embassy who played an influential role in the Bangladesh water sector at that time. Another strong point at the start of PWMP was the formation of an experienced team with international members who knew each other well and who appreciated their expertise and contributions to a common challenge. The cross cultural aspects involved here are the Dutch approach towards participatory water management presented by the Embassy combined with the National Water Policy approach of Bangladesh and experiences of the recruited experts. Understanding and acceptance and a common drive are characteristic for the way these approaches were blended. This may be seen in the perspective of a kind of partnership given the long lasting collaboration of both countries and the role the Dutch played in the water sector of Bangladesh.

Cross cultural collaboration also created specific dynamics in the PWMP team. The western team leader lives for a long time in Bangladesh, speaks the language and is experienced in the water sector. He was able to use these assets for PWMP in combination with his western mindset and personal style. In line with the Dutch and Bangladesh approaches, he and his team developed a clear vision and values on participatory water management, reflected in the strategy of PWMP. This all explains why the team leader was an important and effective driving force behind PWMP, able to integrate experts of different countries as well as their ideas and approaches in the Bangladesh setting. 


\section{Introducing Change as Revitalization Process}

This case shows how cross cultural collaboration has been organized between Bangladesh and The Netherlands and how it introduces and stimulates change by creating the PWMP. The PWMP approach initiated cultural change based on a powerful take off as described. In the view of a revitalization process we recognize increasing stress in Bangladesh about the local water situations. PWMP started when the time was ready, 'cultural distortion' was already present: people experienced stress due to failure in need satisfaction and to uncertainty and anxiety about their situation. Especially local people showed an open mind, willing to learn and change their mental model as well as attitudes and behaviour in relation to the water management situation and day to day activities. The revitalization process was organized in a participative way and elaborated by PWMP in several areas, offering alternative modes of operation and new cultural elements in vision, training and in organizing activities. At the local level transformation took place and still goes on with some support of PWMP in its extended phase in other areas and in relationship with the national water board. Within this board, a specific unit for participatory water management has been formed to support the new developments and to diffuse the approach in different areas. In fact the PWMP was closely related to the change process going on within organizations of the Ministry of Water Resources. Here the discussion about change was more difficult because of long traditions, strong beliefs in practices staff was used to and also interests related to job security and income. Within the national water board not all senior staff was convinced about the participatory approaches, sometimes causing ambiguity and delay as well as confusion at the local level and with PWMP.

The pattern indicated by Wallace and elaborated by Kotter and Heskett as well as Phelan is useful in understanding the change dynamics but also for leading complex change over time. Further exploration and specification in needed to learn more from these dynamics in a cross cultural setting.

\section{Cross Cultural Collaboration and the 'Politics of Culture'}

In the description of PWMP the dynamics of strategy development, decision making, communication and implementation involve different kinds of interaction, leadership, influences, and power play, all referring to power as important aspect of strategizing, organizing and changing. The 'politics of culture' involved in the process of this case refer to decentralization of tasks, to some extend transfer of management, power relations within the PWMP team and in relation to its stakeholders, empowerment of the local people, empowerment of women, constitution of new water management organizations at the local and regional level, with new jobs and functions to be divided up. An interesting issue is that the existing organizations in the water sector have to adapt their modes of operation to a new situation of participatory water management at a local level. These organizations have to adapt to the changing water management situation and demands of local people who will be increasingly trained and organized. We discussed the possible inability to adapt which can be found in the politics of culture, leading to 'cultural lock in' or 'the gradual stiffening of the invisible architecture of the corporation and the ossification of its decision making abilities, control systems and mental models'. We see some indications in this case that this could indeed prevent some organizations in the water sector from making necessary innovations in terms of its products or services and shedding operations with less promising futures. That's why the idea of revitalization is important in a way of ongoing 'mazeway reformulation'. 
The vision and strategy of PWMP as well as the elaboration in the six steps of the change process incorporate important lessons learned and best practices in this respect to be used by other organizations. This point has been recognized by the Government of Bangladesh and by the Dutch Embassy which led to the start up of PWMP in new areas. Also the World Bank uses the experiences of PWMP in its water management improvement project in Bangladesh.

Cross cultural collaboration in complex societal fields as sustainable water resources management shows many dimensions. We tried to unravel organizational dynamics involved in strategizing, organizing and changing which are closely related to societal, administrative and political aspects as well. We are convinced that further research is needed especially in the PWMP problem area which is of vital importance in vulnerable countries in the face of possible climate change. The theoretical exploration and case experiences offer basic insights and in our experience a fruitful perspective for continued research in these complicated challenges.

\section{REFERENCES}

Brown, J.S. and P. Duguid. (1991). Organizational Learning and Communities-of-Practice:

Toward a Unified View of Working, Learning, and Innovation. In: Organization Science, vol. 2, No. 1: 40-57.

Burke, W. (2002). Organization change. Thousand Oaks, Ca: Sage Publications.

Carter, C., S.R. Clegg and M. Kornberger (2008). Strategy as practice? In: Strategic Organization, Vol. 6:83-99.

Chaffee, E.E. (1985). Three Models of Strategy. In: The Academy of Management Review. Vol. 10, No. 1: 89-98.

Crossan, M.M., H.W. Lane and R.E. White. (1997). An Organization Learning Framework: From Intuition to Institution. The Academy of Management Review. Vol. 24, No. 3: 522-537.

Demers, C. (2007). Organization Change Theories. A Synthesis. Thousand Oaks, Ca: Sage Publications.

Flyvbjerg, B. (1998). Rationality and power: democracy in practice. Chicago: The University of Chicago Press

Gioia, D.A. and J.B. Thomas. (1996). Identity, Image, and Issue Interpretation: Sensemaking during Strategic Change in Academia. In: Administrative Science Quarterly. Vol. 41, No. 3: 370403.

Gioia, D.A. and K. Chittipeddi. (1991). Sense making and sense giving in strategic change initiation. In: Strategic Management Journal. Vol. 12, No. 6: 433-448.

Heer, J.M. de. (2009). Organiseren onder druk. Strategie en verandering als expressie van de politics of culture. Amsterdam: VU University Press. 
Heer, J.M. de, A. van Marrewijk and M. Veenswijk. (2009). Making Sense of Complexity in Cross Cultural Collaboration. Unravelling Organizational Dynamics. Essex: Pearson Education Limited.

Heer, J.M. de. (1991). Strategie en verandering in organisaties onder druk. The Hague: VUGA.

Hendry, J. (2000). Strategic Decision Making, Discourse, and Strategy As Social Practice. In: Journal of Management Studies. Vol 37, No. 7: 955-978.

Foster, N. and S. Kaplan. (2001). Creative Destruction: Why Companies That Are built to Last Underperform the Market-and How to Successfully Transform Them. New York:

Currency/Doubleday.

M. Hammersley and P. Atkinson. (1995). Ethnography: principles in practice. London: Routledge.

Islam, N. (2005) Environmental issues in Bangladesh: an overview. Pakistan journal of social sciences, 3 (4): pp. 671-679.

Johnson, G., A. Langley, L. Melin and R. Whittington (eds.). (2007). Strategy as practice. Research Directions and Resources. Cambridge University Press.

Kotter, J.P. (1996). Leading Change. Cambridge: Harvard Business School Press.

Kotter, J.P. and J.L. Hesket (1992). Corporate Culture And Performance. New York: The Free Press.

Lewin, K. (1958). Group Decision and Social Change. New York: Holt, Rinehart and Winston.

Van Marrewijk, A. and M. Veenswijk (2006) The culture of project management. Essex: Pearson Education Limited.

Maitlis, S. and T.B. Lawrence. (2003). Orchestral Manoeuvres in the dark: Understanding failure in Organizational Strategizing. In: Journal of Management Studies. 40(1): 109-139.

Martin, J. (2002). Organization culture: mapping the terrain. Thousand Oaks, Ca: Sage Publications.

Meyerson, D. and J. Martin. (1987). Cultural Change: an Integration Of Three Different Views. In: Journal of Management Studies. Vol. 24, No. 6: 623-647.

Mintzberg, H., B. Ahlstrand, and J. Lampel (1998). Strategy safari. New York: The Free Press.

Narayan - Parker, D. (2002). Empowerment and poverty reduction: a source book. The World Bank, Washington, DC. 
Orlikowski, W.J. (1996). Improvising Organizational Transformation over Time: A Situated Change Perspective. In: Information Systems Research 7 (1): 63-92

Orlikowski, W.J. (2000). Using technology and constituting structures: A practice lens for studying technology in organizations. In: Organization Science, 11(4):404-428.

Pader, E. (2006). Seeing with an ethnographic sensibility: Explorations beneath the surface of public policies. In: Dvora Yanow and Peregrine Schwartz-Shea (eds.). (2006) Interpretation and Method. Empirical Research Methods and the Interpretive Turn. New York: M.E. Sharpe, Inc.

Phelan, J. (2005). A Companion to Narrative Theory. Malden: Blackwell Publishing.

Ritchie, J. and J. Lewis. (2003). Qualitative research practice. London: Sage Publications.

Rouleau, L. (2005). Micro Practices of Strategic Sensemaking and Sensegiving. How Middle Managers Interpret and Self Change Every Day. In: Journal of Management Studies, 42 (7):1413-1441.

Schein, E. (2004). Organization culture and leadership. San Francisco: Jossey-Bas.

Shedroff, N. (2001). Experience Design, New Riders Publishing.

Sztompka, P. (1991). Society in action: the theory of social becoming. University of Chicago Press.

Temple, B. and L. Young (2004). Qualitative Research and Translation Dilemmas. In: Qualitative Research 4 (2): pp. 161-178.

Thompson, P. and P. Sultana (1996). Distributional and social impacts of flood control in Bangladesh. The Geographical Journal, 162 (1): pp. 1-13.

Wallace, A.F.C. (1956). Revitalization Movements. In: American Anthropologist 58, 264-281.

Weick, K. and R. Quinn (1999). Organizational change and development. Annual Review of Psychology, 50 (1): pp. 361-386.

Wilde, K. de. (2000). Out of the periphery. Dhaka: The University Press Limitied.

Whittington, R. (2006). Completing the practice turn in strategy research. In: Organization Studies (5):613-634.

Whittington, R. (1996). Strategy as Practice. In: Long Range Planning, 29(5): 731-735.

Zaman, M. (1993). Rivers of life: living with floods in Bangladesh. Asian Survey, 33 (10): pp. 985-996. 
Yanow, D. and P. Schwartz-Shea. (2006). Interpretation and method. Empirical research methods and the interpretive turn. New York: M.E. Sharpe.

PWMP reports 2003-2010, like Technical Report No. 2 Report of the Institutional Analysis Study; Technical Note No. 8: Formation of Water Management Organization (WMO) in Polders, 22, 43/2 A and 43/2 E; Technical Note No. 9: Sustainable Environmental Management Planning (SEMP) in Polders, 22, 43/2A and 43/2E. 